\title{
Congenital Diaphragmatic Hernia: A Benin Teaching Hospital Experience
}

\author{
L. Bagnan-Tossa' 1 , S. B. Noukpozounkou ${ }^{2}$, S. Mewanou ${ }^{3}$, A. S. C. R. Houegban², \\ H. Koco², R. B. Assan'2, M. A. Fiogbe² \\ ${ }^{1}$ Clinical University of Pediatric and Medical Genetics, CNHU-HKM, Cotonou, Benin \\ ${ }^{2}$ Clinical University of Pediatric Surgery, CNHU-HKM, Cotonou, Benin \\ ${ }^{3}$ Clinical University of Anesthesia and Resuscitation, CNHU-HKM, Cotonou, Benin \\ Email: tossabagn@yahoo.fr
}

How to cite this paper: Bagnan-Tossa, L., Noukpozounkou, S.B., Mewanou, S., Houegban, A.S.C.R., Koco, H., Assan, R.B. and Fiogbe, M.A. (2018) Congenital Diaphragmatic Hernia: A Benin Teaching Hospital Experience. Open Journal of Pediatrics, 8, 25-31.

https://doi.org/10.4236/ojped.2018.81004

Received: December 12, 2017

Accepted: March 4, 2018

Published: March 7, 2018

Copyright (c) 2018 by authors and Scientific Research Publishing Inc. This work is licensed under the Creative Commons Attribution International License (CC BY 4.0).

http://creativecommons.org/licenses/by/4.0/

\begin{abstract}
Congenital diaphragmatic hernia is the outcome of the abdominal contents in the thorax by a breach caused by a failure to close the pleuroperitoneal canal. It is a rare and serious disease. Our teaching hospital had registered these seven last years five cases of congenital diaphragmatic hernia, operated, but never published. We report the most recent one, a case of a newborn baby seen at the 5th hour of life for respiratory distress. Initial examination revealed: an asymmetric thorax, respiratory distress with $88 \%$ oxygen saturation at ambient air, tachycardia and abolition of vesicular murmur in the left lung field. L-abdomen was flat and soft. Thoraco-abdominal radiography revealed a clear left intra-thoracic image with mass effect on the left lung parenchyma. He has benefited from a reduction of the herniated visceras and a successful closing of the breach. The operation had few after-effects after five months follow-up with a very good recovery of the cardio-pulmonary function.
\end{abstract}

\section{Keywords}

Hernia, Diaphragmatic, Congenital

\section{Introduction}

Congenital diaphragmatic hernia is the outcome of the abdominal contents in the thorax by a breach caused by a failure of the closure of the pleuroperitoneal canal. It is a rare disease [1] and severe affecting $1 / 3500$ births with a mortality between $30 \%$ and $60 \%$. Management in a referral center improves the survival of patients [2]. It usually left sided [3]. The symptomatology varies according to the site and the size of the diaphragmatic breach. We report here a case of congenital 
diaphragmatic hernia successfully managed.

\section{Case Description}

It was a newborn baby, referred at the fifth hour of life for a very severe respiratory distress with a SILVERMAN scale rated at $7 / 10$. The gestational history noted a well-attended pregnancy with 7 antenatal consultations, serology (toxoplasmosis, rubella, syphilis, HIV) were negative and the three ultrasounds were normal. The 22-year-old mother, a primigravida, had delivered by Caesarean section at the end of $38 \mathrm{SA}+6$ days for acute foetal suffering with extraction by the cephalic pole of a male newborn baby crying immediately. The APGAR score was 8 in the first minute, 9 in the fifth and 10 in the tenth minute. Neonatal measurements were normal. The amniotic fluid was meconium-strained. The infant had secondarily presented a severe respiratory distress. The initial examination in our center revealed an average general impression, a respiratory distress with respiratory rate at 88 cycles per minute and signs of respiratory struggle, tachycardia at 160 beats per minute, $88 \%$ oxygen saturation at ambient air. The thorax was discreetly asymmetric with an abolition of vesicular murmur in the left lung field and a flat, soft abdomen. The thoraco-abdominal radiography revealed a clear left intra-thoracic image with erasure of the left diaphragmatic dome; mass effect on the left pulmonary parenchyma rolled upwards and on the mediastinum organs deviated to the right (Figure 1). The diagnosis of left diaphragmatic hernia was posed indicating a surgical cure. Hospitalized in neonatology unit, under oxygen therapy at $5 \mathrm{~L} / \mathrm{min}$ by an endotracheal tube in right lateral decubitus, the respiratory state remained stable. At the abdominal laparotomy on the 5th day of life, part of the abdominal viscera (stomach, spleen, left lobe of the liver, left half of the left transverse colon, left part proximal part of the descending colon) leaving the thorax by a left diaphragmatic breach measuring $5 \mathrm{~cm}$ by $4 \mathrm{~cm}$ (Figure 2). There were no other visceral abnormalities. A reduction of the hernia had been made, which made it possible to recover a hernial sac consisting of the pleura and the parietal peritoneum; then a closure of the breach by separate points at Mersuture 2.0 on a thoracic drain with anti-reflux system (Figure 3). The operation had few after-effects with a complete regression of the respiratory distress. The thoraco-abdominal X-ray, performed on the third day after surgery, noticed a good left lung expansion with the clearance of the mass effect on the mediastinum; the right pulmonary parenchyma was healthy (Figure 1). Clinical examination was normal after five months follow-up with a very good cardio-pulmonary function. Sociodemographic characteristic and signs of the patient were resumed in Table 1.

\section{Discussion}

Its frequency is 1 case for 2000 to 5000 live births [1]. It accounts for $8 \%$ of all major congenital anomalies [4]. In $90 \%$ of cases the diaphragmatic defect is posterolateral and in $80 \%$ of cases it is on the left [ $2=\mathrm{D} 3]$. The sex ratio is 2 [5]. In our case, the subject was male and the defect was postero left lateral. 


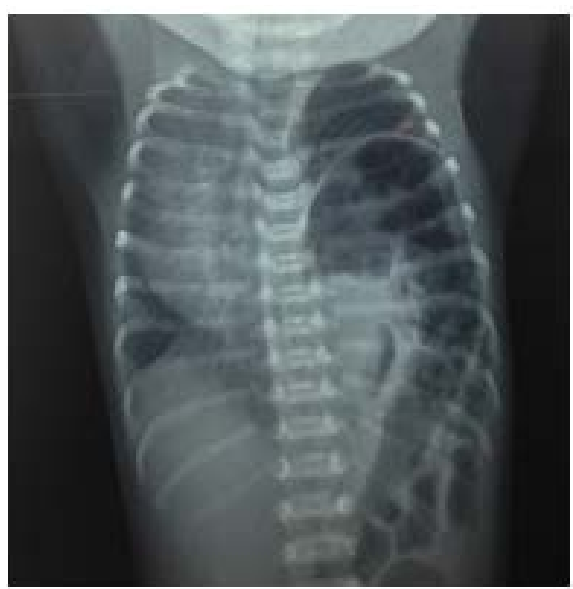

(a)

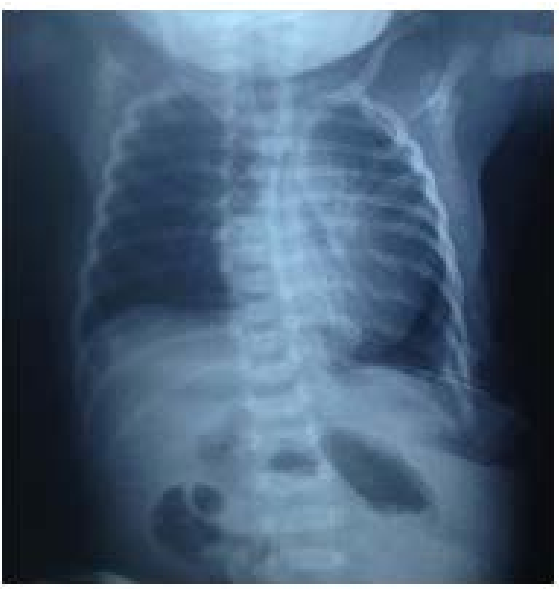

(b)

Figure 1. Thoraco-abdominal X-ray of face. (a) Pre-operative thoraco-abdominal X-ray showing intra thoracic clarity and heart and big vessels deviated on the right; (b) Post-operative thoraco-abdominal X-ray performed on the third day after surgery showing good left lung expansion. With clearance of the mass effect on the mediastinum. Right pulmonary parenchyma was healthy.

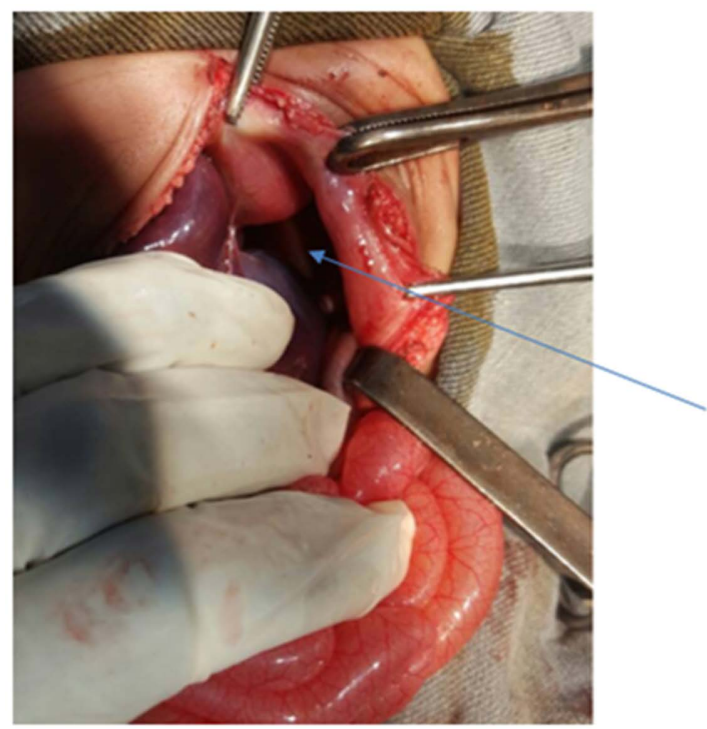

Left diaphragmatic breach

Figure 2. Per operative picture showing a left diaphragmatic breach.

Its etiology is still unknown in most cases. There is a family association in $2 \%$ of cases. In $15 \%$ of cases, there are chromosomal abnormalities. Recently, it was discovered that the $15 \mathrm{q} 26$ region is involved in the development of the diaphragm [4]. Trisomies 13, 18 and 21 are the genetic associations most often found. $40 \%$ of congenital diaphragmatic hernias are associated with major malformations (cardiac, musculoskeletal, neurological, genitourinary) [6]. In our case, there was no major malformation associated with it.

Pulmonary hypoplasia begins in embryonic period even before the formation of the diaphragm. It is aggravated by the presence of the abdominal organs in the thorax. The anomalies also concern the upper airways which are under developed, 


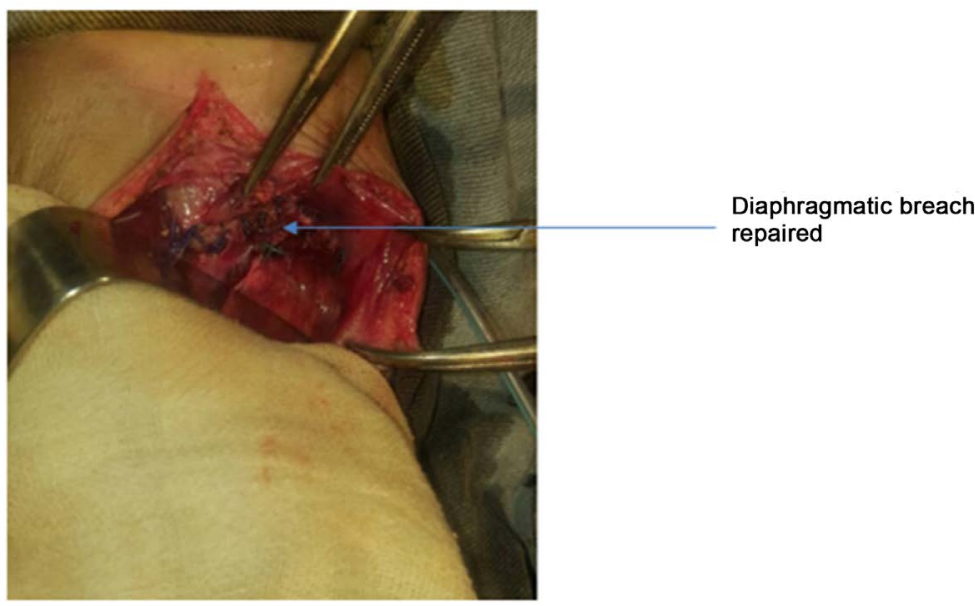

Figure 3. Per operative picture showing the diaphragmatic breach repaired.

Table 1. Sociodemographic characteristics and signs.

\begin{tabular}{|c|c|}
\hline & Case description \\
\hline Age & $5^{\text {th }}$ hour of life \\
\hline Sex & Male \\
\hline Antenatal diagnosis & No \\
\hline Circumstances of occurred & Very severe respiratory distress \\
\hline & $\begin{array}{l}\text { Clinical signs: average general impression, Respiratory distress } \\
\text { with } 88 \% \text { oxygen saturation at ambient air, Asymmetric thorax }\end{array}$ \\
\hline Signs & $\begin{array}{l}\text { Thoracoabdominal X-ray: clear left intrathoracic image, mass } \\
\text { effect on the left pulmonary parenchyma, mediastinum organs } \\
\text { deviated to the right }\end{array}$ \\
\hline Treatment & $\begin{array}{l}\text { Preoperative care } \\
\text { Reduction of the hernia, closure of the breach by laparotomy }\end{array}$ \\
\hline Evolution & $\begin{array}{l}\text { Few after-effects with complete regression of the respiratory } \\
\text { distress }\end{array}$ \\
\hline
\end{tabular}

the intra-pulmonary arteries which are reduced per unit of pulmonary volume and whose walls are thickened.

Antenatal diagnosis of congenital diaphragmatic hernia is possible from the second quarter of pregnancy, and is based on the presence of the stomach or intestines in the thorax. This diagnosis can be difficult in the absence of an intra-thoracic stomach or when the diaphragmatic defect is on the right side [3]. In our case, 3 ultrasounds were performed which did not reveal abnormalities. The research of associated malformations in antenatal, especially cardiac and musculoskeletal is useful to assess the prognosis. In the search for chromosomal abnormality, amniocentesis is useful.

After birth, the clinical signs are variable according to the size and site of the diaphragmatic breach; but also of the volume of herniated abdominal organs. When there is a large breach, the symptomatology is noisy with a respiratory distress syndrome made of dyspnea, cyanosis and tachycardia, present from birth. This respiratory distress is at the origin of a distension of the intra-thoracic digestive 
loops; which exerts additional pressure on the hypoplastic lung. When the breach is small, the symptomatology may be mute for several months, and the diagnosis of diaphragmatic hernia is fortuitous in the context of the exploration of digestive or respiratory manifestations. When the breach is located on the right side, the diagnosis is often difficult because of the presence of the liver which prevents the penetration of the abdominal contents into the thorax [7]. In our case, this was a large breach on the left side with a large part of the abdominal contents in the thorax. The clinical picture was that of early respiratory distress.

On the para-clinical level, chest X-ray or better with a naso-gastric tube can be used to diagnose [8]. This diagnosis can be confirmed by oeso-gastro-duodenal transit, which shows an opacification of the stomach in the thorax, but this examination fails to underestimate the degree of hernia [9]. Scanning and scintigraphy of the liver and spleen are useful for diagnosis in right diaphragmatic hernias [10].

In preoperative management, respiratory assistance is provided by intubation and ventilation with low inspiratory pressure (less than $25 \mathrm{~cm}$ of water) to minimize lung damage and maintain oxygen saturation above $85 \%$. Oxygenation by bezel or mask is contraindicated due to the gastric distension it generates. The installation of a naso-gastric tube with a gentle aspiration is useful to ensure decompression of the digestive tract [8]. Extracorporeal membrane oxygenation is used in cases of severe hypoxia and stabilization of newborn babies before and during surgery [11]. Nitric oxide is a selective pulmonary vasodilator used to improve oxygenation in patients with pulmonary hypertension [12]. Surgical management now delayed 24 to 48 hours to ensure clinical stabilization and a fall of the pulmonary hypertension; consists of a closing of the diaphragmatic breach by suture or by a prosthesis [13].

Patient care was provided by the placement of a naso-gastric tube and oxygenation by endotracheal tube in right lateral decubitus which allowed the respiratory state to be maintained until surgery. The surgical cure was performed by laparotomy on the 5th day of life with drainage of the diaphragmatic space.

A laparoscopic surgical cure has been described in the literature for late-onset cases in stable patients [14].

The development of the operated diaphragmatic hernia is enamelled by complications. There are respiratory complications (bronchopulmonary dysplasia, pulmonary arterial hypertension, bronchospasms, and recurrent respiratory infections); digestive complications (gastroesophageal reflux); neurological complications; musculoskeletal complications (scoliosis, pectus excavatus or carinatus); a growth retardation [15] [16].

Mortality is $48 \%$ in isolated forms; association with a malformation or prematurity aggravates the prognosis with a mortality of $80 \%$ and $83 \%$ respectively [17]. This last decade, our teaching hospital had registered five cases of congenital diaphragmatic hernia which all had been operated with a mortality of $20 \%$. This good falsely mortality rate could be explained by the smallness of our number.

Thanks to advances in prenatal diagnosis and early multidisciplinary care, 
survival is $80 \%$ [18].

\section{Conclusion}

This clinical fact questions us because of the severity and the rarity of congenital diaphragmatic hernia in Benin. It points out the benefit of the possibility of antenatal diagnosis using classic obstetric ultrasounds. Its treatment is surgical by an abdominal approach. Its prognosis depends on the cardiac and pulmonary malformations which may be associated with it and which must be systematically investigated.

\section{References}

[1] Jain, V., Agarwala, S. and Bhatnagar, V. (2010) Recent Advances in the Management of Congenital Diaphragmatic Hernia. Indian Journal of Pediatrics, 77, 673-678. https://doi.org/10.1007/s12098-010-0094-1

[2] Skari, H., Bjornland, K., Haugen, G., Egeland, T. and Emblem, R. (2000) Congenital Diaphragmatic Hernia: A Meta-Analysis of Mortality Factors. Journal of Pediatric Surgery, 35, 1187-1197. https://doi.org/10.1053/jpsu.2000.8725

[3] King, H. and Booker, P.D. (2005) Congenital Diaphragmatic Hernia in the Neonate. Continuing Education in Anaesthesia, Critical Care \& Pain, 5, 171-174. https://doi.org/10.1093/bjaceaccp/mki045

[4] Doyle, N.M. and Lally, K.P. (2004) The CDH Study Group and Advances in the Clinical Care of the Patient with Congenital Diaphragmatic Hernia. Seminars in Perinatology, 28, 174-184. https://doi.org/10.1053/j.semperi.2004.03.009

[5] Kitano, Y., Lally, K.P. and Lally, P.A. (2005) Late-Presenting Congenital Diaphragmatic Hernia. Journal of Pediatric Surgery, 40, 1839-1843.

https://doi.org/10.1016/j.jpedsurg.2005.08.023

[6] Keijzer, R., Liu, J., Deimling, J., Tibboel, R. and Post, M. (2000) Dual-Hit Hypothesis Explains Pulmonary Hypoplasia in the Nitrofen Model of Congenital Diaphragmatic Hernia. American Journal of Pathology, 156, 1299-1306.

https://doi.org/10.1016/S0002-9440(10)65000-6

[7] Bagłaj, M. (2004) Late-Presenting Congenital Diaphragmatic Hernia in Children: A Clinical Spectrum. Pediatric Surgery International, 20, 658-669. https://doi.org/10.1007/s00383-004-1269-5

[8] Chan, H.Y., Wong, C.C. and Ng, F. (2009) Late-Presenting Congenital Diaphragmatic Hernia: A Potentially Life Threatening Case. Hong Kong Journal of Emergency Medicine, 16, 102-105. https://doi.org/10.1177/102490790901600208

[9] Shimizu, T., Hira, S., Hirooka, S., Yonekura, T. and Tamai, H. (2002) Late Onset of Right Bochdalek's Hernia with Strangulation of the Omentum. Acta Paediatrica, 91, 483-485. https://doi.org/10.1111/j.1651-2227.2002.tb01675.x

[10] Baglaj, M. and Dorobisz, U. (2005) Late-Presenting Congenital Diaphragmatic Hernia in Children: A Literature Review. Pediatric Radiology, 35, 478-488. https://doi.org/10.1007/s00247-004-1389-z

[11] Davis, P.J., Firmin, R.K., Manktelow, B., Goldman, A.P., Davis, C.F., Smith, J.H., et al. (2004) Long-Term Outcome Following Extracorporeal Membrane Oxygenation for Congenital Diaphragmatic Hernia: The UK Experience. Journal of Pediatrics, 144, 309-315. https://doi.org/10.1016/j.jpeds.2003.11.031

[12] The Neonatal Inhaled Nitric Oxide Study Group (NINOS) (1997) Inhaled Nitric 
Oxide and Hypoxic Respiratory Failure in Infants with Congenital Diaphragmatic Hernia. Pediatrics, 99, 838-845. https://doi.org/10.1542/peds.99.6.838

[13] Rozmiarek, A.J., Qureshi, F.G., Cassidy, L., Ford, H.R. and Hackam, D.J. (2004) Factors Influencing Survival in Newborns with Congenital Diaphragmatic Hernia: The Relative Role of Timing of Surgery. Journal of Pediatric Surgery, 39, 821-824. https://doi.org/10.1016/j.jpedsurg.2004.02.010

[14] Lansdale, N., Alam, S., Losty, P.D. and Jesudason, E.C. (2010) Neonatal Endosurgical Congenital Diaphragmatic Hernia Repair: A Systematic Review and Meta-Analysis. Annals of Surgery, 252, 20-26. https://doi.org/10.1097/SLA.0b013e3181dca0e8

[15] Pennaforte, T., Rakza, T., Sfeir, R., Aubry, E., Bonneville, M. and Fayoux, P. (2012) Hernie de coupole diaphragmatique: Devenir respiratoire et vasculaire pulmonaire. Revue Des Maladies Respiratoires, 29, 337-346. https://doi.org/10.1016/j.rmr.2011.07.009

[16] Bagolan, P. and Morini, F. (2007) Long-Term Follow up of Infants with Congenital Diaphragmatic Hernia. Seminars in Pediatric Surgery, 16, 134-144. https://doi.org/10.1053/j.sempedsurg.2007.01.009

[17] Kassab, B., Denovec, S., Arnould, P., Claris, O., Chappuis, J.P. and Thoulon, J.M. (2000) Diagnostic prenatal de la hernie des coupoles diaphragmatiques: évaluation pronostic. Journal de Gynécologie Obstétrique et Biologie de la Reproduction, 29, 170-175.

[18] Zupan Simunek, V., Razafimahefa, H., Chabernaud, J.L., Boithias-Guerot, C., Caeymaex, L., Coquery, S., et al. (2017) Avancées médicales et progrès des techniques en réanimation néonatales. EMC-Obstétrique, Dans, 1-21. Article 5-114-K-60. 